\title{
Evaluation of Development Index of China's VC Industry Based on Weight Optimization Algorithm and TOPSIS
}

\author{
Yi Sun $\mathbb{D}^{1},{ }^{1}$ Long-Long Zhou $\mathbb{D}^{2},{ }^{2}$ Shan $Z$ Zhu, ${ }^{3}$ Jin-Tao Su $\mathbb{D}^{1},{ }^{1}$ and Jing Zhang ${ }^{1}$ \\ ${ }^{1}$ School of Finance, Anhui University of Finance and Economics, Bengbu 233030, China \\ ${ }^{2}$ School of Urban Geology and Engineering, Hebei GEO University, Shijiazhuang 050031, China \\ ${ }^{3}$ School of Business, Hong Kong Baptist University, Hong Kong 999077, China \\ Correspondence should be addressed to Jing Zhang; zhangjingseuc@163.com
}

Received 15 May 2021; Accepted 5 June 2021; Published 12 June 2021

Academic Editor: Huihua Chen

Copyright (C) 2021 Yi Sun et al. This is an open access article distributed under the Creative Commons Attribution License, which permits unrestricted use, distribution, and reproduction in any medium, provided the original work is properly cited.

\begin{abstract}
After more than 20 years of rapid growth in China's venture capital industry, huge market development potential and boost by the digital wave have made China one of the most attractive venture capital markets in the world. At present, most of the measurement and evaluation of the development level of China's venture capital industry are qualitative evaluations and few quantitative evaluations, and the evaluation indicators are unitary. It is difficult to comprehensively measure the development status of the entire venture capital industry. This paper constructs a comprehensive evaluation model of China's venture capital industry development index to reflect the development status of the entire industry, while dynamically tracking its future development trends. In the index system of China's venture capital industry development index model, there are a total of ten indicators in three aspects: total, structural, and performance dimension. The calculation results are obtained by subjective and objective weighting target planning algorithm, and the final score evaluated by TOPSIS model is indexed. In this way, the development curve of China's venture capital industry from 2006 to 2016 is obtained. Judging from the results reflected in the model conclusions, the index can better reflect the current development trend and problems faced by China's venture capital industry.
\end{abstract}

\section{Introduction}

Venture capital (VC for short) is rapidly developing. There is no clear and unanimous conclusion on the difference between $\mathrm{VC}$ and private equity (PE). It is generally considered that the investment mainly in the early and midstage of the company belongs to $\mathrm{VC}$, while those that are invested in the expansion or mature stage belong to $\mathrm{PE}$ investment. In practice, the actual business of PE and VE overlaps, penetrates each other, and does not have a clear boundary. Moreover, it is difficult to clearly divide the development stage of an enterprise. In recent years, PE investment has also moved forward. The investment scope and exit situation of some PEs and VCs are similar. Therefore, this article does not make a strict distinction between PE and VC, both of which are classified as VC $[1,2]$.

China's VC industry started relatively late. Under the guidance of national macroeconomic policies, China's VC industry has entered a period of rapid development. In 2017, the VC industry of China raised more funds than the US market. In summary, VC has played an important role in China's economic innovation and development. However, China's VC is mainly manifested in the rapid growth of quantity and scale, and there is a clear gap in the quality of development compared with Western developed countries [3-13]. It is necessary to establish an efficient, reasonable, and timely development evaluation system. Through reasonable and timely evaluation, problems arising in the development of VC can be discovered and optimized in a timely manner. In this regard, some scholars such as ChangZhong analyzed from a qualitative perspective [13-17], and Xiao-Feng proposed the equity investment industry index and rating from a quantitative perspective, with a focus on rating the VC enterprise level [18], but the above academic literature undoubtedly provides a reference for this article.

This article firstly builds the index of VC industry in China. Secondly, considering the deficiencies weighting method used in the existing literature, this method is more efficiency and 
reasonable. Further, starting from the availability of data, this paper selects relevant data of China's VC industry from 2006 to 2016 for empirical evaluation and analysis.

\section{Literature Review}

The VC industry is attracting more and more attention from academia. Scholars explore VC based on diverse subject theoretical perspectives and research methods. Scholars such as [19] used scientific knowledge graphs to visualize the domestic VC literature collected by China Knowledge Network (CNKI) from 1992 to 2019. They believed that China's research hotspots around the 1990s were of significance and ways of developing VC. To study more the relationship between $\mathrm{VC}$ and financial management, enterprise management, technological innovation, and so on, scholars such as [20] combed through relevant domestic and foreign literature and found that there are more studies in three aspects: VC and macroeconomics, VC institutions and startup enterprises, and VC institutions themselves. There are relatively few studies in the existing literature on the overall development of the VC industry itself, and fewer use quantitative research and analysis.

Scholars such as Yan-Ni [21] also believe that compared with the diversified technology financial system that has been formed in my country, which is dominated by financial intermediaries, VC, multilevel capital markets, and other important supplements, it is a statistical system that quantifies financial support for scientific and technological innovation activities at a relatively lagging level.

$\mathrm{Yi}[22]$ believes that to analyze the development level of a country's VC industry, we must not only compare the total amount of VC, but also consider its support for both small and high-tech enterprises in the country, and we must exclude different economies. Therefore, the literature [22] proposed to use the VC Development Index (VCDI) to measure the development level of a country's VC industry. VCDI includes two indicators: (1) financing index (FI) and (2) technology index (TI). The financing index refers to the proportion of a country's $\mathrm{VC}$ investment in the early stages (including the seed period and the establishment period). The technology index refers to the proportion of a country's VC invested in high-tech industries (mainly refers to the computers, communication industries, and biomedicine industries).

As an evaluation study similar with the VC industry, Wen-Sen [23] proposed that the scientific and technological financial statistical system not only has aggregate indicators, but also a series of structural indicators. Xiao-Li [24] proposed that a core system of scientific and technological financial statistical indicators should be constructed at different levels and from multiple perspectives. On the basis of accurately measuring and dividing the levels of technology, finance, and government, it refines and constructs a concise and complete technology financial support system and analyzes the role positioning of all parties in the development of technology and finance. Wei-Zhen et al. [25] showed that the financial structure, the development level of technology finance, the effect of technology finance, and the technology finance environment are four aspects to build a comprehensive evaluation index system for technology finance. Scholars such as Jian-Hui [26] believe that the design of science and technology financial indicators not only has the characteristics of a general development indicator system, but also has its uniqueness. In the selection of indicators, the literature [26] selected 18 indicators in 3 dimensions of scientific and technological output, investment and financing system, and support system.

Similarly, Svirydzenka [27] established a more rigorous and comprehensive indicator system for the financial development index. A total of 9 indicators were selected and divided into three levels in order to evaluate the development of the financial systems of various countries at different levels of abstraction. At the lowest level, set financial institution depth (FID), accessibility (FIA), and financial institution efficiency (FIE), as well as financial market depth (FMD), accessibility (FMA), and financial market efficiency (FME) to measure financial depth, accessibility, and effectiveness of institutions and markets. These indicators are aggregated into two subindexes in the middle layer-Financial Institution Index (FI) and Financial Market Index (FM). Finally, the two subindexes are aggregated into an overall index of Financial Development (FD).

Through combing the existing literature, this article believes that the research methods in the existing literature can be improved. First, establish comprehensive indicators for the development of the VC industry, and add more indicators that better reflect the development of the industry on the basis of the original literature. Second, the private equity nature of VC has led to a lot of information in the industry that is nonpublic and difficult to obtain. Based on the availability of data, this article makes an empirical evaluation of VC industry development.

\section{Construction of Indicators for VC Industry Development Index}

Development evaluation is a dynamic process, and a common evaluation method is to measure the dynamic process by constructing an index. For example, stock index, as far as investors are concerned, the price change trend of stock index can be understood. The index evaluation method is also widely used in other fields to reflect the connotation of the comprehensive concept and the development of the dynamic process, and the measurement itself is continuous and will not cause information loss. This on the one hand reflects the comprehensive concept because multiple indicators can be integrated; on the other hand, it also reflects the dynamic process of development-the index can continuously reflect the development trend of a stage. Moreover, there is no "cap" in indexation. Compared with the rating method [18], it can not only reflect the improvement and improvement process but also show the infinite nature of such improvement and improvement.

3.1. Construction of Indicators. To measure the development of an object, it is necessary to consider the two aspects of "quantity" and "quality." On the one hand, the 
increase in quantity is the most intuitive manifestation of development and perfection. There is no increase in absolute quantity, and development cannot be discussed. On the other hand, there is only an increase in quantity without quality improvement, and it is not efficient and high-quality development. Therefore, based on the principles of systematic, scientific, operability, etc., the construction of the risk investment industry development index evaluation index system consists of the target layer, the criterion layer, and the indicator layer. Based on the concept of the risk investment industry development index proposed in the literature [21], the risk investment industry development index is determined as the target layer. Refer to the literature [22-25] to construct the criterion layer, namely, the total risk investment index, the risk investment performance index, and the risk investment structure index. The criterion layer contains ten three-level indicators, as shown in Figure 1.

3.1.1. Total Amount Index. The index measures the development of China's VC industry from the perspective of volume. As a quantitative indicator to measure the development and evolution of the VC industry, the larger the value is, the more talents and funds in the society are actively entering the VC industry, and the VC industry will grow stronger and livelier. The faster the VC industry develops, the more abundant funds are provided to innovation entities such as technology-based enterprises, and the more professionals provide value-added services to the invested enterprises. Specific indicators include the following:

(1) Management Funds Scale (MFS). It is used to reflect the total amount of funds invested by the whole society and foreign capital in China. The sources of funds generally include nonfinancial capital, banks, insurance companies, securities companies, trust companies, and other capital such as foreign capital.

(2) Cumulative Total Investment (CTI). It is used to reflect the actual amount of funds used for investment. The investment targets cover companies at various stages before the listing, with the focus on new startups. During the startup and development stages of an enterprise, a large amount of capital is needed to support its innovation.

(3) Number of Registered Professionals (NRP). It reflects the total number of talents entering the VC industry. Talents in the VC industry usually have high academic qualifications, multiple professional backgrounds, and work experience in multiple fields. The total number of talents reflects the speed of the industry's growth.

(4) Number of Institutions (NS). It includes two aspects, one is the number of VC management institutions, and the other is the number of funds. The greater the number of institutions entering the VC industry, the more active the response industry, and the more quantitative changes leading to qualitative changes.
3.1.2. Performance Index. It is used to reflect the investment management capabilities and returns of the VC industry and to determine the sustainability of the growth of the total capital of the VC industry. It is an important reference indicator for the development and improvement of the VC industry. The index also reflects the investment returns of various VC entities. Higher investment performance can provide guarantee for its further fundraising; higher return on investment of market entities has a wealth demonstration effect and can attract original investors and new investors to enter the VC industry. Specific indicators include the following:

(5) Average Annual Return (AAR). It refers to the ratio of the annual average return to the original investment, which can better reflect the return on investment in the entire industry. In the VC industry, because of the poor financial information disclosure of investment entities and invested companies, and the long exit time period, it is usually difficult to obtain the exit rate of return data for each VC fund.

(6) Number of Quits (NQ). It reflects the weak liquidity characteristics of long-term equity investment, and the number of quits in the entire industry each year reflects the strength of liquidity.

3.1.3. Structure Index. The index mainly measures the transformation and upgrading of the VC industry from quantitative change to qualitative change. The optimization of the structure focuses on adjusting the proportional relationship and optimizing the internal structure. After more than 20 years of development, China's VC industry has not been long compared with Western developed countries. However, its rapid development was mainly in the 10 years from 2008 to 2017, which can be called the "golden decade" of China's VC industry. In 2017, China's VC industry raised more funds than the US market. In summary, the second largest VC market is China after 2017. VC has played an important role in the innovation and development of China's economy. However, the domestic VC market is mainly manifested in the rapid growth of quantity and scale, and its development quality is comparable to that of the West. Compared with countries, there is a significant gap [13]. The sustainable and healthy development of China's VC industry largely depends on whether the industry structure is reasonable. The structural indicators of the VC industry are based on their own perspective, reflecting the market structure and the economic role. Whether the resources of the VC industry are balanced and effective in the allocation is the standard to measure whether the structure of the VC industry is reasonable. Specific indicators include the following:

(7) Investment Intensity (II). It refers to the ratio of cumulative investment to the country's gross domestic product (GDP). It reflects the position of the $\mathrm{VC}$ industry in the entire national economy. Its size depends not only on the increase in investment, but also on the overall economic development. Speed, 


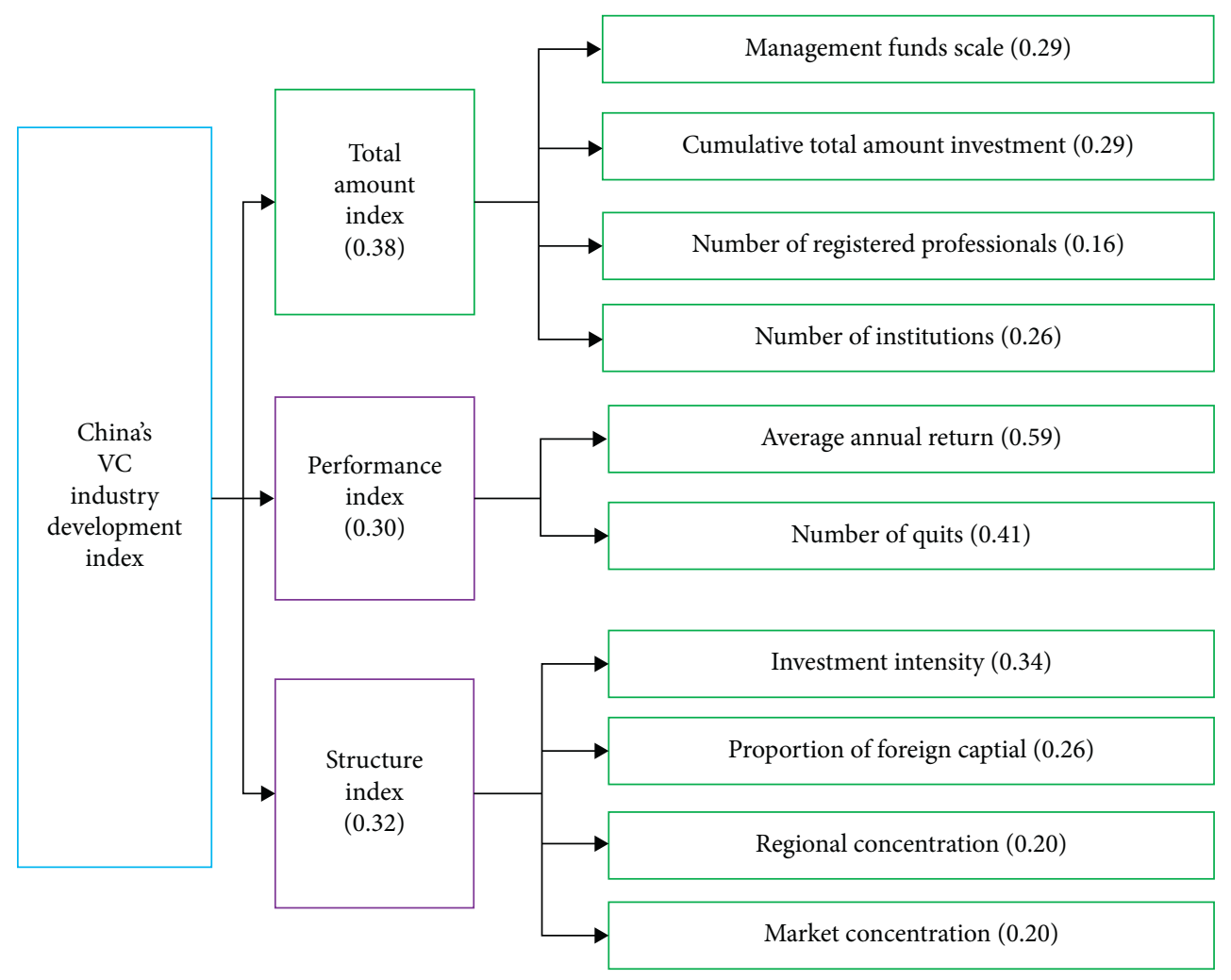

FIGURE 1: Evaluation indicator system of VC industry development index.

therefore, also indirectly reflects the development potential of a country's VC market.

(8) Proportion of Foreign Capital (PFC). It reflects the degree of internationalization of China's VC industry, and the degree of international capital entering China reflects the externality of China's VC industry.

(9) Regional Concentration ( $R C)$. It calculates the percentage of the total management funds of the top four provinces or cities in the country. This indicator reflects the differences in the level of development of China's VC in different regions. Obviously, the larger the indicator, the more uneven the development of $\mathrm{VC}$ in various regions. The reasons for the unbalanced development level of $\mathrm{VC}$ are very complex. In addition to the unbalanced level of economic development, the regional financial market environment, industrial policies, regional population development, social security level, differences in the process of economic system reform, and differences in regional cultural concepts, etc. all are important reasons.

(10) Market Concentration (MC). It uses the commonly used absolute concentration indicator, which is the percentage of the total number of VC institutions in the top four provinces or cities in the industry to the total number of institutions. This indicator is the same as regional concentration, reflecting the difference in the level of development of China's VC in different regions. Obviously, the larger the indicator, the more uneven the development of VC in various regions.

3.2. Weight of Index and Indicators. Regarding indicator and index weights, subjective weighting methods represented by Delphi and Analytic Hierarchy Process (AHP) can reflect the attitude of the evaluator, but they are subjectively arbitrary. The objective weighting method represented by principal component analysis (PCA), entropy method (Entropy), fuzzy mathematics (Fuzzy), and complex correlation coefficient method has a strong mathematical theoretical basis. The objective weighting method can make full use of data information and avoid the subjective arbitrariness of the weighting results, but sometimes it cannot reflect the wishes of the evaluators. Therefore, subjective and objective weighting methods have their own characteristics, but both have certain limitations. Literature [28] adopts the goal programming method to optimize the algorithm, which combines subjective and objective weighting to determine the weight of each indicator, which can overcome the shortcomings of a single weighting method. This article uses this method.

Assuming there are $m$ indicators, the weight of the $j$ th indicator is $W_{j}$; each indicator has $n$ data, and the indicator weight vector calculated by the subjective weighting method AHP is

$$
W_{j}^{\prime}=\left[W_{1}^{\prime}, W_{2}^{\prime}, \ldots, W_{m}^{\prime}\right] \text {, and satisfied } 0 \leq W_{j}^{\prime} \leq 1, \sum_{j=1}^{m} W_{j}^{\prime}=1 .
$$


AHP method is very traditional and simple, and the index weights calculated by this method are omitted here.

The indicator weight vector calculated by the objective weighting method entropy method is

$$
W_{j}^{\prime \prime}=\left[W_{1}^{\prime \prime}, W_{2}^{\prime \prime}, \ldots, W_{m}^{\prime \prime}\right] \text {, and satisfied } 0 \leq W_{j}^{\prime \prime} \leq 1, \sum_{j=1}^{m} W_{j}^{\prime \prime}=1 .
$$

The indicator weights calculated by the entropy method are shown in Table 1 .

Let $\alpha$ and $\beta$ denote the coefficients of $W^{\prime}$ and $W^{\prime \prime}$, respectively, and combine the subjective weight vector and the objective weight vector to make

$$
\left\{\begin{array}{l}
W=\alpha W^{\prime}+\beta W^{\prime \prime} \\
0 \leq W_{j} \leq 1, \sum_{j=1}^{m} W_{j}=1
\end{array}\right.
$$

According to the weighting rule of comprehensive evaluation, the target value of each evaluation is calculated as follows:

$$
\left\{F_{j}=\sum_{j=1}^{m} a_{i j}\left(\alpha W^{\prime}+\beta W^{\prime \prime}\right), i=1,2, \ldots, n ; \quad j=1,2, \ldots, m .\right.
$$

Among them, $a_{i j}$ is the $i$ th value of the $j$ th index, $F_{j}$ is the evaluation value, and the following multiobjective programming model is constructed:

$$
\begin{cases}\operatorname{Max} & F=f_{1}, f_{2}, \ldots, f_{n}, \\
\text { s.t. } & \left\{\begin{array}{l}
\alpha^{2}+\beta^{2}=1 \\
\alpha, \beta \geq 0
\end{array}\right.\end{cases}
$$

The abovementioned multiobjective decision-making planning model can be equivalent to a single-objective optimization model using the linear weighting method with equal weights:

$$
\left\{\begin{array}{cc}
\operatorname{Max} \quad F=\sum_{i=1}^{n} \sum_{j=1}^{m} a_{i j}\left(\alpha W_{j}^{\prime}+\beta W_{j}^{\prime \prime}\right), \\
\text { s.t. } & \left\{\begin{array}{l}
\alpha^{2}+\beta^{2}=1, \\
\alpha, \beta \geq 0 .
\end{array}\right.
\end{array}\right.
$$

The model can be solved by constructing a Lagrange function:

$$
L=\sum_{j=1}^{m} \sum_{i=1}^{n} a_{i j}\left(\alpha W_{j}^{\prime}+\beta W_{j}^{\prime \prime}\right)+\frac{\omega}{2}\left(\alpha^{2}+\beta^{2}-1\right) .
$$

$\omega$ is the Lagrange multiplier. Find the partial derivatives of $\alpha$ and $\beta$, and set $\partial L / \partial \alpha=0, \partial L / \partial \beta=0$; the values of the optimal solution $\alpha$ and $\beta$ of the optimization model can be obtained:

$$
\left\{\begin{array}{l}
\alpha=\frac{\sum_{i=1}^{n} \sum_{j=1}^{m} a_{i j} W_{j}^{\prime}}{\sqrt{\left(\sum_{i=1}^{n} \sum_{j=1}^{m} a_{i j} W_{j}^{\prime}\right)^{2}+\left(\sum_{i=1}^{n} \sum_{j=1}^{m} a_{i j} W_{j}^{\prime \prime}\right)^{2}}}, \\
\beta=\frac{\sum_{i=1}^{n} \sum_{j=1}^{m} a_{i j} W_{j}^{\prime \prime}}{\sqrt{\left(\sum_{i=1}^{n} \sum_{j=1}^{m} a_{i j} W_{j}^{\prime}\right)^{2}+\left(\sum_{i=1}^{n} \sum_{j=1}^{m} a_{i j} W_{j}^{\prime \prime}\right)^{2}}} .
\end{array}\right.
$$

After normalizing $\alpha$ and $\beta$, the following formula is obtained:

$$
\left\{\begin{array}{l}
\alpha^{*}=\frac{\alpha}{\alpha+\beta}, \\
\beta^{*}=\frac{\beta}{\alpha+\beta} .
\end{array}\right.
$$

Substituting formulae (9) into (3), the optimized attribute weight $w_{j}$ can be obtained.

\section{Empirical Study}

This paper uses China's VC development data from 2006 to 2016 to conduct an empirical study on the evaluation index system of the VC industry development index.

4.1. Data Source. In the evaluation index system, the data of ten three-level indicators included in the total index, performance index, and structure index are derived from the "China Venture Capital Development Report," "China Venture Capital Industry Development Report," and "China Venture Capital Yearbook."

\subsection{Data Processing and Calculation}

4.2.1. Dimensionless Processing of Raw Data. For the indicator $a_{i j}$, the positive indicator is processed as follows:

$$
a_{i j}^{\prime}=\frac{a_{i j}-\min \left(a_{i j}\right)}{\max \left(a_{i j}\right)-\min \left(a_{i j}\right)} .
$$

Reverse indicators are handled as follows:

$$
a_{i j}^{\prime}=\frac{\max \left(a_{i j}\right)-a_{i j}}{\max \left(a_{i j}\right)-\min \left(a_{i j}\right)} .
$$

4.2.2. Weight Calculation. According to the weight optimization algorithm in Section 3.2, the dimensionless data is calculated to obtain the weights of each index and criterion level. The final result of the optimized weight is shown in Figure 1; this result is then used by the TOPSIS method.

4.2.3. Evaluation of TOPSIS Method. The Technique for Order of Preference by Similarity to Ideal Solution (TOPSIS) method is used for comprehensive evaluation. This method uses the positive ideal solution and negative ideal solution of 
TABLE 1: The indicator weights calculated by the entropy method.

\begin{tabular}{|c|c|c|c|c|c|c|c|c|c|c|}
\hline \multicolumn{11}{|c|}{ Indicators } \\
\hline Time & MFS & CTI & NRP & NS & AAR & NQ & II & PFC & $\mathrm{RC}$ & FC \\
\hline 2006 & 0.0000 & 0.0000 & 0.0000 & 0.0000 & 0.0082 & 0.0000 & 0.0109 & 1.0000 & 0.0000 & 0.8996 \\
\hline 2007 & 0.0590 & 0.0253 & 0.1157 & 0.0224 & 0.0000 & 0.0939 & 0.0000 & 0.7296 & 0.6444 & 0.9654 \\
\hline 2008 & 0.1040 & 0.1070 & 0.2601 & 0.0700 & 0.6867 & 0.1468 & 0.1836 & 0.6036 & 0.5012 & 0.7699 \\
\hline 2009 & 0.1236 & 0.1477 & 0.4084 & 0.1359 & 0.3634 & 0.3514 & 0.2485 & 0.5163 & 0.0716 & 0.6056 \\
\hline 2010 & 0.2289 & 0.3221 & 0.5924 & 0.2206 & 0.8111 & 0.4188 & 0.5789 & 0.1527 & 0.4296 & 0.4717 \\
\hline 2011 & 0.3329 & 0.4847 & 0.8178 & 0.3071 & 1.0000 & 0.5391 & 0.7637 & 0.0000 & 0.6921 & 0.0000 \\
\hline 2012 & 0.3480 & 0.5796 & 0.9774 & 0.4929 & 0.9610 & 0.5499 & 0.8368 & 0.5925 & 0.1360 & 0.7676 \\
\hline 2013 & 0.3822 & 0.6628 & 1.0000 & 0.6253 & 0.2308 & 0.7365 & 0.8184 & 0.5277 & 0.8831 & 1.0000 \\
\hline 2014 & 0.6001 & 0.7521 & 0.9096 & 0.7094 & 0.4634 & 0.7136 & 0.8597 & 0.6164 & 1.0000 & 0.4327 \\
\hline 2015 & 0.7867 & 0.8796 & 0.9052 & 0.8412 & 0.6797 & 0.9386 & 0.9431 & 0.5151 & 0.8353 & 0.3821 \\
\hline 2016 & 1.0000 & 1.0000 & 0.7524 & 1.0000 & 0.6143 & 1.0000 & 1.0000 & 0.5459 & 0.3055 & 0.6068 \\
\hline$W_{j}^{\prime \prime}$ & 0.1350 & 0.1267 & 0.0793 & 0.1467 & 0.0999 & 0.0936 & 0.1069 & 0.0592 & 0.0995 & 0.0530 \\
\hline
\end{tabular}

the evaluation problem to rank the evaluation objects [29]. The calculation process of the TOPSIS method is as follows:

(1) Construct a weighted normative evaluation matrix for the dimensionless data $A=\left[a_{i j} W_{j}\right]$.

(2) Construct positive ideal solution $A_{j}^{+}$and negative ideal solution $A_{j}^{-}$.

$$
\left\{\begin{array}{l}
A_{j}^{+}=\left(a_{j}^{+}\right)_{1 \times m}=\max \left(a_{i j} W_{j}\right), \\
A_{j}^{-}=\left(a_{j}^{-}\right)_{1 \times m}=\min \left(a_{i j} W_{j}\right) .
\end{array}\right.
$$

(3) Calculate the distance from each evaluation object to the positive ideal solution and the negative ideal solution.

The distance to the positive ideal solution is

$$
D_{i}^{+}=\sqrt{\sum_{j=1}^{m}\left(a_{i j}-a_{j}^{+}\right)^{2}}, \quad i=1,2, \ldots, n .
$$

The distance to the negative ideal solution is

$$
D_{i}^{-}=\sqrt{\sum_{j=1}^{m}\left(a_{i j}-a_{j}^{-}\right)^{2}}, \quad i=1,2, \ldots, n .
$$

(4) Calculate the relative closeness of each evaluation object to the ideal solution:

$$
D_{i}=\frac{D_{i}^{-}}{D_{i}^{-}+D_{i}^{+}}, \quad i=1,2, \ldots, n
$$

4.3. Empirical Results. Perform comprehensive weighting according to the above weights to obtain the total VC industry index, VC industry performance index, VC industry structure index, and VC industry development index from 2006 to 2016, as shown in Figures 2-5.

This paper analyzes the calculation results of various subindexes and comprehensive development indexes of China's VC industry from 2006 to 2016 and finds the following:

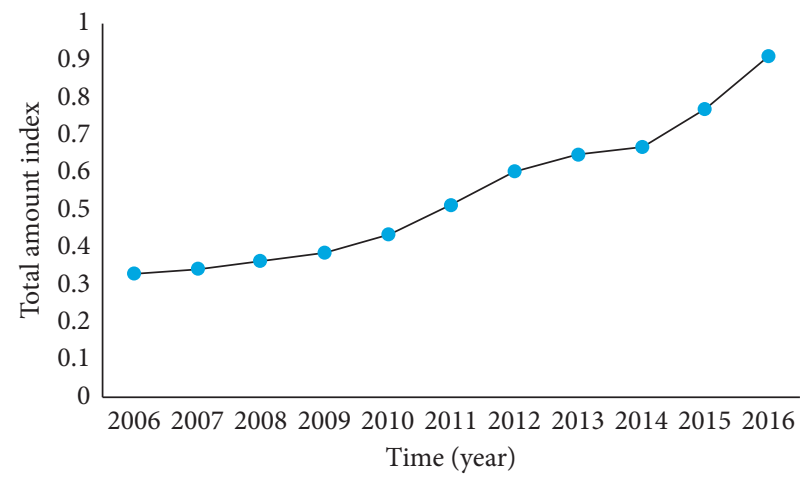

FIGURE 2: 2006-2016 total amount index.

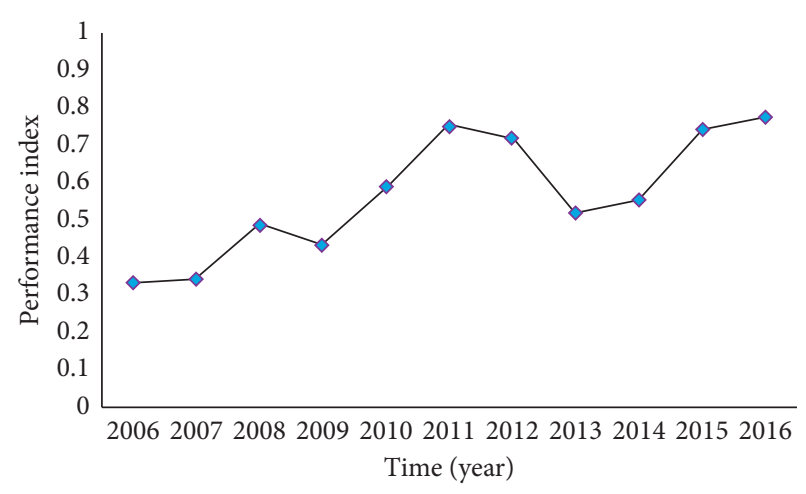

FIgURE 3: 2006-2016 performance index.

(1) The total amount index of China's VC industry has shown a rapid upward trend year by year. Looking back at the development history of China's VC industry, the government-led and policy-driven characteristics are obvious. It received the support of relevant government departments and the attention of people from all walks of life and set off an upsurge in the development of VC in my country. In June 2007, the revised "Partnership Law" was implemented and the limited partnership system was formally introduced. After more than ten years, the number of VC funds in China has rapidly increased, and the team of 


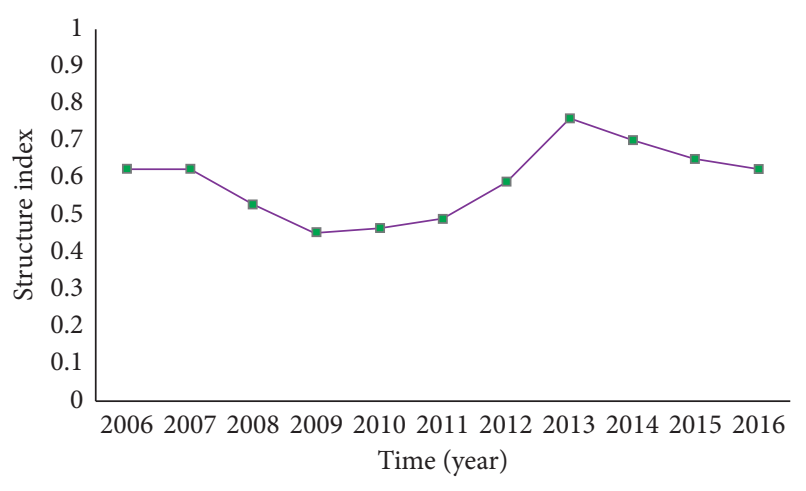

FiguRe 4: 2006-2016 structure index.

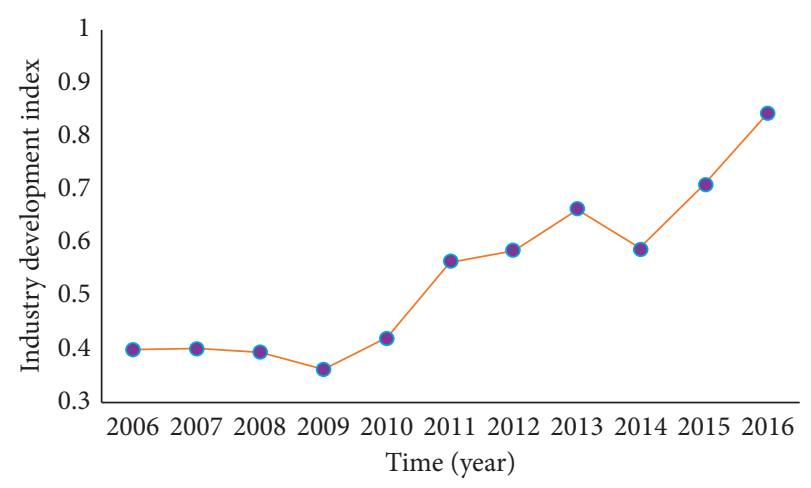

Figure 5: 2006-2016 China’s VC industry development index.

limited partners has continued to grow. At the same time, the continuous emergence of technological innovation, stable market growth, and deeper international cooperation have given Chinese VC funds an explosive growth of investment opportunities.

(2) The performance index of China's VC industry showed rapid growth from 2006 to 2011 and showed certain fluctuations from 2011 to 2016 but tended to stabilize. This shows that the investment management capabilities of market entities in China's VC industry have been improved in practice and have achieved better investment performance. Although various investment myths are often exploded in the market, from the perspective of the entire industry, performance is still maintained at a certain level. In the long run, the performance of the VC industry is generally better than that of public equity funds. At the same time, large number of investors have poured into it. This also explains the rapid development of China's VC industry aggregate index from another aspect.

(3) China's VC industry structure index did not change significantly from 2006 to 2011. From 2011 to 2013, it showed a clear upward trend. In 2013, the industry experienced a deep consolidation, and the development of the industry became more rational. There was a slight downward trend from 2013 to 2016, indicating that the structural optimization process of China's VC industry was slow. China's VC industry has not yet realized the optimal adjustment and transformation from quantitative change to qualitative change. From the perspective of internal structure, VC funds and M\&A funds still account for a relatively small proportion of China's VC funds. As the market continues to differentiate and accelerate clearing, industry concentration is also undergoing significant changes.

(4) From 2006 to 2016, China's VC industry development index showed an overall upward trend. As a major change in the technology capital market, the official launch of the GEM in October 2009 played an important role in promoting the development of China's VC industry, which was reflected in the significant increase in China's VC industry index in 2010. Various local governments have implemented a lot of government support policies and measures to support VC. In 2016, China embarked on a new path to implement the innovation-driven development strategy and intensively issued lots of systematic, high-level, programmatic policy documents for innovation and entrepreneurship.

This is by far the most comprehensive and systematic programmatic document for the development of VC. It provides a solid institutional guarantee for further promoting VC to grow stronger and better. These good policies drove the rapid rise of China's VC industry development index from 2009 to 2016. Based on the above, it can be judged that China's VC industry is in an optimized development stage under the guidance of the government.

4.4. Suggestions. Although China's VC industry index is generally on the rise and has played an important role in China's economic innovation and development, there is still a significant gap in the development quality of China's VC industry compared with Western developed countries. According to the "Global Private Equity Report 2020" (GLOBAL PRIVATE EQUITY REPORT 2020, English version) released by the world-renowned consulting firm Bain \& Company, global private equity institutions will need to work hard to further improve the quality of development in the future. China's VC industry needs to focus on structural improvement and optimization.

(1) Policy-driven and strengthened supervision should be synchronized. After continuous national policydriven, China's VC industry has developed rapidly, but the legalization of industry supervision and the legalization of the development environment need to continue to be improved.

(2) Handle the relationship between internal development and external competition. As China further reforms and opens up, especially in the context of the opening of the financial industry to the outside world, it is necessary to strengthen competition with many outstanding international $\mathrm{VC}$ institutions under international rules, which requires China's VC industry to be more professional. 
(3) Optimize the structure of state-owned capital and social capital, guide the orderly entry of foreign capital, and increase the investment scale of individuals and mixed-ownership enterprises.

(4) The weak liquidity of the VC industry requires China to continue to optimize the exit channels of the capital market, vigorously promote the company's listing and registration system, and vigorously develop the PE secondary market.

(5) Focusing is on the fundraising, investment, management, and retirement of China's VC industry and related intermediaries, technology financial institutions, and further improving the industry's ecosystem.

\section{Conclusion}

This paper designs a complete, scientific, and practical evaluation index system for the development of China's VC industry. The objective planning algorithm is used to comprehensively optimize the subjective and objective weights obtained based on the AHP and entropy method, and the subindex and development index are obtained by weighting. Based on the development data of China's VC industry from 2006 to 2016, empirical research is conducted, and it is finally judged that China's VC industry is in an optimized development stage under the guidance of the government. Through the analysis of the application of the evaluation index system, which can be seen as based on the index system, the overall development trend of China's VC industry can be judged, and the development trend of China's VC industry total index, performance index, and structural index can also be calculated. The evaluation index system can dynamically monitor the development and evolution of VC in China and various provinces and cities and provide a scientific reference for the government to promote the development of VC in decisionmaking and policy formulation.

\section{Data Availability}

The data used to support the findings of this paper are included within the article.

\section{Conflicts of Interest}

The authors declare that they have no conflicts of interest regarding the publication of this paper.

\section{Authors' Contributions}

All authors contributed equally to this paper.

\section{Acknowledgments}

This paper was supported by open research fund of the State Key Laboratory for Management and Control of Complex Systems (20200103) and doctoral research startup fund of Anhui University of Finance and Economics (85051).

\section{References}

[1] X. Y. Zhang and L. Liao, "VC's backgrounds, IPO underpricing and post-IPO performance," Economic Research Journal, vol. 46, no. 6, pp. 118-132, 2011.

[2] S. Chen, W. L. He, and R. Zhang, "Venture capital and enterprise innovation: influence and potential mechanism," Management World, vol. 33, no. 1, pp. 158-169, 2017.

[3] R. P. Pradhan, M. B. Arvin, M. Nair, S. E. Bennett, S. Bahmani, and J. H. Hall, "Endogenous dynamics between innovation, financial markets, venture capital and economic growth: evidence from Europe," Journal of Multinational Financial Management, vol. 45, no. 1, pp. 15-34, 2018.

[4] G. Bing, P. C. David, and T. S. Anna, "Firms' innovation strategy under the shadow of analyst coverage," Journal of Financial Economics, vol. 131, no. 2, pp. 456-483, 2018.

[5] K. Ivalina, M. Ping, and P. Shagun, "Innovation: the interplay between demand-side shock and supply-side environment," Research Policy, vol. 47, no. 2, pp. 440-461, 2018.

[6] G. Aygunes, "Evaluation venture capital investment and macroeconomic variables via stepwise regression method," AIP Conference Proceedings, vol. 1978, no. 1, pp. 1-4, 2018.

[7] H. Qiao, G. Z. Wang, and S. Y. Wang, "Can venture capital screen and foster entrepreneurial firms? empirical evidence from fuzzy regression discontinuity," Systems Engineering-Theory \& Practice, vol. 40, no. 12, pp. 3059-3079, 2020.

[8] X. M. Yuan and H. Y. Zhang, "Research on the mechanism of risk investment promoting regional innovation and development-based on the perspective of patent and high-tech industry," Qinghai Social Sciences, vol. 39, no. 3, pp. 113-119, 2018.

[9] L. Yao, "Venture capital, regional technological innovation level and spatial effects-an empirical study based on interprovincial panel data," Contemporary Economic Management, vol. 40, no. 6, pp. 7-12, 2018.

[10] S. X. Bai and T. Chen, "Research on the mechanism of venture capital's effect on enterprise innovation," Economic System Reform, vol. 36, no. 3, pp. 1994-1998, 2018.

[11] J. H. Sun and J. Du, "The dynamic equilibrium relationship between venture capital, R \& D input and knowledge output from the perspective of time lag effect: an empirical analysis based on co-integration and VECM model," Science and Technology Progress and Policy, vol. 35, no. 15, pp. 9-15, 2018.

[12] Z. X. Hu and A. J. Wang, "Research on the leveraging effect of venture capital on the efficiency of new energy technology innovation," Science and Technology Progress and Countermeasures, vol. 35, no. 23, pp. 82-91, 2018.

[13] C. Z. Sun, "The urgency and breakthrough of the high-quality development of China's private equity industry," Management Aspects, vol. 20, no. 2, pp. 69-72, 2020.

[14] S. J. Zhang, X. D. Li, and H. H. Yu, "The research on PE's functions and future development pattern in China," Nanjing Social Sciences, vol. 25, no. 6, pp. 23-28, 2014.

[15] K. Y. Han, "Research on the development direction of private equity investment in China," Modern Economic Research, vol. 33, no. 3, pp. 15-18, 2014.

[16] S. Y. Li, "Development status and suggestions of private equity investment funds in China," Times Finance, vol. 38, no. 2, pp. 24-26, 2017.

[17] N. Hao and L. Cheng, "Analysis and suggestions on the development status of private equity investment funds in China," Journal of Shanxi University of Finance and Economics, vol. 36, no. s1, pp. 33-34, 2014. 
[18] X. F. He, Research on Equity Investment Industry Index and Rating, China Development Press, Beijing, China, 2015.

[19] X. R. Zhang, R. Shen, and J. Y. Lu, "Venture capital research: overview and prospects," Foreign Economics and Management, vol. 41, no. 4, pp. 58-70, 2019.

[20] Y. N. Feng and P. L. Shen, "Research on technology and finance innovation of Shanxi high-tech industrial development zone," Economic Issues, vol. 41, no. 1, pp. 81-89, 2019.

[21] Y. Tan, "Analysis on the transition process and the development level of China's venture capital institution," Studies in Science of Science, vol. 21, no. s1, pp. 95-100, 2003.

[22] W. S. Li, "The construction and practice of scientific and technological financial statistics system," Financial Development Research, vol. 33, no. 4, pp. 28-36, 2014.

[23] X. L. Yang, "Research on the core system of scientific and technological financial statistical indicators and related financial crimes," Journal of Qingyuan Vocational and Technical College, vol. 9, no. 2, pp. 53-59, 2016.

[24] W. Z. Liang and S. Z. Liang, "Research on the comprehensive evaluation index system of science and technology finance," Science and Technology Business Monthly, vol. 27, no. 10, pp. 64-67, 2014.

[25] J. H. Yang, Q. Y. Li, and J. Y. Xie, “The evaluation index system of regional science and technology finance development-based on the analysis of projection pursuit model," Science and Technology Management Research, vol. 40, no. 6, pp. 69-74, 2020.

[26] K. Svirydzenka, "Introducing a new broad-based index of financial development," IMF Working Papers, vol. 16, no. 5, p. 1, 2016.

[27] Y. Sun and H. F. Huang, "Algorithm of adjusting weights of decision-makers and attribute in multi-attribute group decision-making," in Proceedings of the 25th China Control and Decision Conference, pp. 4145-4149, Guiyang, China, May 2013.

[28] W. Cai, X. C. Zhao, L. H. Cai, and Y. C. Zhong, "Statistical measurement on economic efficiency of China's strategic emerging industries," Statistics \& Decision, vol. 37, no. 7, pp. 98-102, 2021.

[29] Z. Q. Peng, X. Y. Zhao, and L. W. Wang, "The research progress of China's venture capital and the visual analysis of the frontier," Friends of Accounting, vol. 38, no. 19, pp. 101107, 2020. 